\title{
Avoidance learning as a function of amount and direction of change in CS intensity without a constant background intensity*
}

\author{
JAMES P. JAMES \\ Fort Hays Kansas State College, Hays, Kans. 67601 \\ and

\section{PETER OSSENKOP and WALTER W. MOSTOWAY University of Manitoba, Winnipeg, Man., Canada}

A procedure of presenting changes in CS intensity with variable background intensities, as developed by Grice, Masters, \& Kohfeld (1966), was used in a shuttle avoidance task with 13 rats as Ss. Superior performance resulted from increases in stimulus intensity in comparison to decreases. Amount of change in stimulus intensity $(10$ or $20 \mathrm{~dB})$ was positively related to performance only when the change involved increases in the intensity of stimulation.

A novel experimental procedure was employed by Grice, Masters, \& Kohfeld (1966) in investigating the effects of amount and direction of change in CS intensity on human eyelid conditioning. The three levels of stimulus intensity used by these investigators were a soft and a loud $1,000-\mathrm{Hz}$ tone and a nonstimulus condition. Each CS was a change from one level of stimulus intensity to another, which remained in effect during the intertrial interval. The next CS was a change in intensity from this intertrial level to a different intensity. Thus, there were six changes in stimulus intensity serving as CSs and three levels of intertrial intensities.

Grice et al (1966) suggested that the use of their procedure constituted a test of the Perkins (1953) and Logan (1954) generalization of inhibition hypothesis of stimulus intensity dynamism (SID). This position asserts that the SID effect is produced by generalization of inhibition from an unreinforced zero-intensity intertrial stimulus. In Grice's procedure, since each of the three stimulus intensities serves as the unreinforced intertrial stimulus for equal tıme periods, equivalent amounts of inhibition should become associated with each intensity. The Perkins-Logan position predicts no differences in performance to the six CSs. Yet, Grice et al found that conditioning was most reliably related to the amount of change in stimulus intensity. These findings agree with the results of other conditioning experiments using human Ss (Champion, 1962, 1967; Logan \& Wagner, 1962), but conflict with certain animal studies (Kish, 1955; Schwartz, 1958). Kish found that avoidance performance was superior with light or buzzer onset as

*This research was supported by Grant APA-223 from the National Research Council of Canada. Reprint requests should be sent to J. P. James, Department of Psychology, Western Illinois University, Macomb, Ill. 61455.
CS in comparison to stimulus offset. Schwartz's data indicated that both direction and amount of change in CS intensity influenced avoidance learning.

In the present experiment, the procedure of Grice et al (1966) was adapted for use in a shuttle avoidance setting with rats as Ss. The attempt here was to evaluate this procedure further and to explore the generality of their findings in a different learning context with a different species of Ss.

\section{METHOD \\ Subjects}

The Ss were 13 experimentally naive male Sprague-Dawley rats, 90-120 days of age. They were housed in individual cages and maintained on ad lib Purina Lab Chow and water.

\section{Apparatus}

The apparatus consisted of a shuttle box, $30 \times 30 \times 90 \mathrm{~cm}$. The sides were of unpainted plywood, and the ceiling was screen wire. The grid floor was constructed of brass rods, $3.2 \mathrm{~mm}$ in diam and spaced $12.7 \mathrm{~mm}$ center to center. Photoelectric cells and light sources were mounted $11.4 \mathrm{~cm}$ on either side of the midline in such a manner that the light beams crossed the chamber parallel to the midline. A white-noise CS from a Grason-Stadler 901B generator was delivered from a speaker located over the center of the chamber. Shock was produced by a Grason-Stadler E1064GS generator. From an adjacent equipment room, the $E$ could observe the $S$ through a one-way-vision screen and operate the semiautomated programming equipment. A Brüel \& Kjaer Model 2203 sound-level meter, set to the linear fast scale, was used to measure and calibrate the sound intensities.

\section{Procedure}

The average ambient sound level in the experimental chamber was $65 \mathrm{~dB}$. The three intensities of white noise were 70,80 , and $90 \mathrm{~dB}$. A CS was a change in stimulus intensity from one of these intensities of white noise to another, which remained on during the intertrial interval until the next change. Intertrial intervals were, randomly, $30,35,40,45,50,55$, or $60 \mathrm{sec}$, with a mean of $45 \mathrm{sec}$.

In general, the basic procedure for CS presentation followed that of Grice et al (1966). One sequence of 96 trials was fashioned which consisted of eight blocks of 12 trials. Within each block, the order of presentation of the shifts in stimulus intensity, serving as the CSs, was determined randomly, with the restriction that each change occur twice within each block. There were 16 occurrences of each stimulus change. Within the sequence, each S's first conditioning trial was determined randomly. All 96 trials were administered to each $S$ in a single session.

A session started with the placement of a $S$ in the conditioning chamber while one of the intertrial stimuli was in effect. After $1 \mathrm{~min}$, the first CS, a shift to another intensity, occurred. If the $S$ crossed the midline and interrupted the far-side light beam within $5 \mathrm{sec}$ of CS presentation, shock was withheld. Failure to execute an avoidance response produced the $0.8-\mathrm{mA}$ grid shock which terminated when the $\mathrm{S}$ made an escape response by crossing the light beam. 


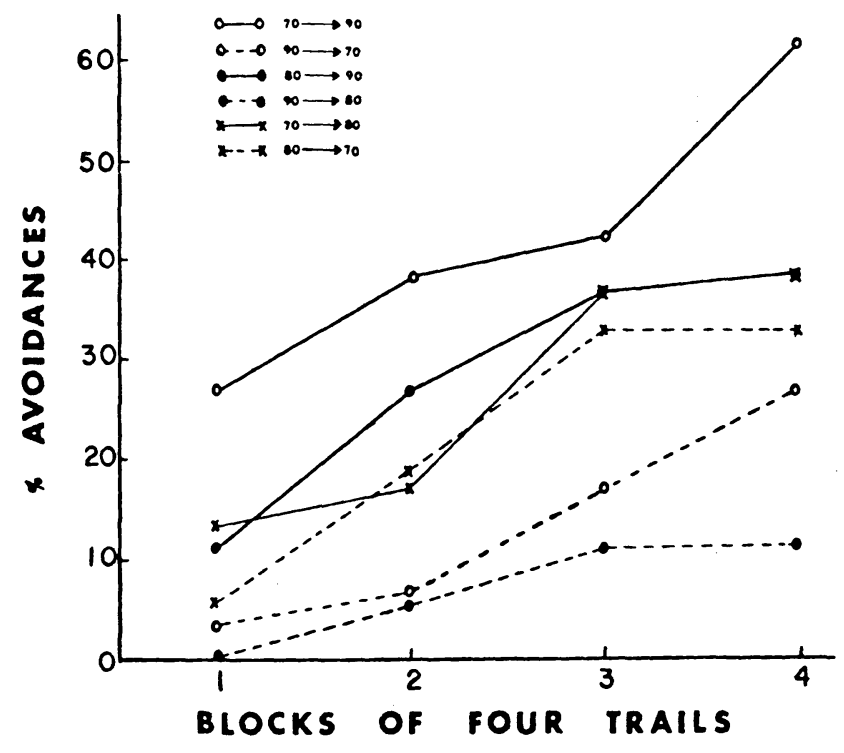

Fig. 1. Percentage avoidances across trial blocks for each change in stimulus intensity.

\section{RESULTS}

In Fig. 1, mean percentage avoidance responses are plotted across trial blocks for each of the six changes in stimulus intensity used as CSs. Each data point represents four observations on each S. Reliable overall avoidance conditioning is suggested by a significant difference in number of avoidances between Block 1 and Block $4(\mathrm{t}=4.09, \mathrm{df}=12, \mathrm{p}<.01)$. The data of Fig. 1 suggest that increases in stimulus intensity, indicated by solid lines, produced better avoidance performance as compared to decreases in stimulus intensity, depicted by broken lines. A 2 by 3 (Direction by Change) repeated

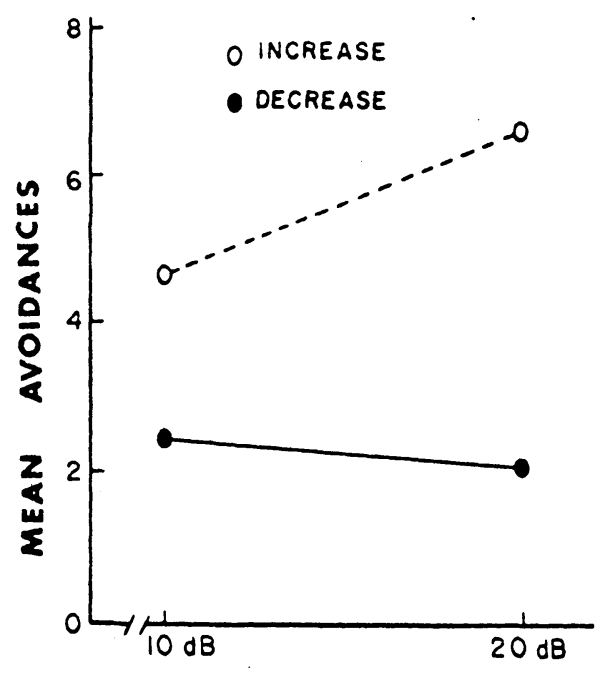

\section{AMOUNT OF CHANGE}

Fig. 2. Mean avoidances for increases and decreases in stimulus intensity as a function of amount of change in stimulus intensity. measures analysis of variance, similar to that used by Grice et al (1966), was performed on number of avoidances summed across trials. The two levels of the direction factor were increases and decreases in stimulus intensity. The three levels of the change factor were the intensities of stimulation involved in any change, i.e., 70 and $80 \mathrm{~dB}, 80$ and $90 \mathrm{~dB}$, and 70 and $90 \mathrm{~dB}$. Direction of change was highly significant $(F=36.75, d f=1 / 12$, $p<.001)$. A reliable change main effect $(F=5.04$, $\mathrm{df}=2 / 24, \quad \mathrm{p}<.025)$ and Direction by Change interaction $(\mathrm{F}=10.35, \mathrm{df}=2 / 24, \mathrm{p}<.001)$ were also found.

The data were cast into a 2 by 2 Direction of Change (increase or decrease) by Amount of Change (10 or $20 \mathrm{~dB})$ repeated-measures design. The mean number of avoidance responses for each $S$ to stimulus intensity increases of $70-80$ and $80-90 \mathrm{~dB}$ were used as the $10-\mathrm{dB}$ increase data. Likewise, means of the $90-80$ and 80-70 $\mathrm{dB}$ increases were used as the 10- $\mathrm{dB}$ decrease data. Figure 2 illustrates the mean number of avoidance responses to changes in stimulus intensities of 10 or $20 \mathrm{~dB}$ as a function of increases or decreases in stimulus intensities. The repeated-measures analysis of variance performed on these data yielded a dramatically significant direction of change effect $(F=49.64$, $\mathrm{df}=1 / 12, \mathrm{p}<.001)$. Although amount of change failed to reach significance $(\mathrm{F}=4.51, \mathrm{df}=1 / 12, \mathrm{p} \geq .05)$, the interaction was reliable $(F=7.12, \mathrm{df}=1 / 12, \mathrm{p}<.025)$.

The mean number of crossings recorded during the intertrial stimuli of 70,80 , and $90 \mathrm{~dB}$ were $7.77,9.38$, and 9.62 , respectively. These values did not differ significantly $(F=1.04, \mathrm{df}=2 / 24, \mathrm{p}>.25)$.

\section{DISCUSSION}

The present data suggest that increases in stimulus intensity were more effective as CSs in comparison to intensity decreases. Amount of change in CS intensity appeared to be positively related to performance only when the change involved an increase in intensity; amount of change did not affect performance differentially for decreases in stimulus intensity.

The reliable direction-of-change effect found here agrees with Kish (1955), who did not examine extent of change. However, the present results contrast with the findings of Schwartz (1958). In a between-Ss design, Schwartz found that amount of change affected performance more than direction of change. However, the greater intensity effects reported in the present study may be expected because of the within-Ss design used (Grice \& Hunter, 1964).

The present results also contrast with studies using human Ss (Champion, 1962, 1967; Logan \& Wagner, 1962; Grice et al. 1966). But, as suggested by Grice \& Hunter (1964), the louder stimuli may possess greater attention-evoking ability for rats than for human Ss. Or, as Kimble (1961) has pointed out. verbal mediation by human Ss may serve to equate subjectively stimuli of different intensities, which would serve to attenuate differences in the intensity of stimulation.

It is difficult to account for the present observations in terms of either the Perkins-Logan hypothesis of SID or the adaptation-level interpretation (Grice \& Hunter, 1964), since increases in stimulus intensity, as opposed to decreases, led to bettter performance. Hull's (1949) theory of SID, that performance is a positive function of stimulus intensity. may best account for these results. 
The foregoing points are tempered by the observation that the obtained differences appeared in the first block of trials. These differences in performance then proceded from different levels on the first block across the ensuing trial blocks with little evidence of any divergence. It could be assumed that the intensity factor produced an interaction effect during this first block of trials. However, it was not possible to determine whether or not this was the case because of the low performance obtained. It is clear that this question merits further investigation.

In conclusion, the procedure of Grice et al (1966) may offer a viable approach to investigate the effects of stimulus variables on animal learning when control of background stimulation appears warranted.

\section{REFERENCES}

Champion, R. A. Stimulus-intensity effects in response evocation. Psychological Review, 1962, 69, 428-449.

Champion, R. A. Reduced stimulus intensity as a CS in GSR conditioning. Journal of Experimental Psychology, 1967, 73, 631-632.

Grice, G. R., \& Hunter, J. J. Stimulus intensity effects depend upon the type of experimental design. Psychological Review, $1964,71,247-256$.

Grice, G. R., Masters, L., \& Kohfeld, D. L. Classical conditioning without discrimination training: A test of the generalization theory of CS intensity effects. Journal of Experimental Psychology, 1966, 72, 510-513.

Hull, C. L. Stimulus intensity dynamism (V) and stimulus generalization. Psychological Review, 1949, 56, 67-76.

Kimble, G. A. Hilgard and Marquis' Conditioning and learning. New York: Appleton-Century-Crofts, 1961.

Kish, G. B. Avoidance learning to the onset and cessation of conditioned stimulus energy. Journal of Experimental Psychology, 1955, 50, 31-38.

Logan, F. A. A note on stimulus intensity dynamism (V). Psychological Review, 1954, 61, 77-80.

Logan, F. A., \& Wagner, A. R. Direction of change in CS in eyelid conditioning. Journal of Experimental Psychology, $1962,64,325-326$.

Perkins, C. C., Jr. The relation between conditioned stimulus intensity and response strength. Journal of Experimental intensity and response strength.

Schwartz, M. Conditioned-stimulus variables in avoidance learning. Journal of Experimental Psychology, 1958, 55, 347-351.

(Received for publication April 25, 1973.)

\section{Social attraction among and between albino and hooded rats*}

\author{
BIBB LATANÉ, JOHN EDWARDS $\dagger$, \\ CLAUDE STEELE $\dagger \dagger$, and DAVID WALTON $\dagger+\dagger$ \\ Ohio State University, Columbus. Ohio 43210
}

Cross- or within-strain pairs of albino and hooded rats were allowed to affiliate freely in an open field. All rats, whether male or female, albino or hooded, were highly gregarious, and this gregariousness increased over days. Although hooded rats showed more defecation and immobility than did albinos, there were no differences in overall social attraction, and rats in cross-strain pairs did not differ from rats in same-strain pairs. The results suggest that emotionality does not necessarily lead to affiliation in rats and that sociability does not depend on similarity of such static stimulus characteristics as fur color.

Male albino rats are very much attracted to other male albino rats. When tested in same-sex pairs in an open field, they stay much closer to each other than would be expected by chance (Latané, 1969) and often spend upwards of $50 \%$ of their time in direct physical contact. The attraction exhibited by male albino rats increases over days of testing, probably because competing exploratory and fear responses drop out as the field becomes familiar (Eckman, Meltzer, \& Latané, 1969; Latané \& Walton, 1972). These results are well established for male albino rats; it is unknown whether they also hold for females or for other rat strains.

Male albino rats appear to reduce fear for each other. They defecate less when tested in pairs than when tested alone and show less immobility or freezing (Latané, 1969; Latané \& Glass, 1968; Latané, Joy, Meltzer, Lubell, \& Cappell, 1972; Latané, Poor, \& Sloan, 1971; Latané \& Werner, 1971). This opens up the possibility

*This research was partially supported by NSF Grants GS 1239 and GS 2292. Request reprints from Bibb Latané, 404-C West 17th Ave., Columbus, Ohio 43210.

+ Now at Loyola University, Chicago, Ill. 60626.

+ Now at University of Utah, Salt Lake City, Utah 84112.

$++N$ ow at Marshall University, Huntington, w. Va. 27501. that fear reduction is a motivation for social approach in rats. If so, then it might be expected that rats differing in fearfulness should also differ in gregariousness. Hooded rats typically show greater signs of emotionality than do albino rats (Wilcock \& Broadhurst, 1967); it is unknown whether they also show greater sociability.

Male albino rats are much more attracted to other male albino rats than they are to a variety of nonsocial objects, whether moving or still (Latané \& Glass, 1968), familiar or unfamiliar (Latané, Poor, \& Sloan, 1971), warm or cold, or previously associated with positive reinforcement or not (Latane \& Werner, 1971). These results suggest that the movement of another rat, its responsiveness, or the opportunity to interact with it may be important determinants of social attraction. It would be interesting to see whether albino rats are also attracted to rats of another strain or whether there is any intrinsic preference for a member of one's own strain, independent from its responsiveness or the opportunity for interaction.

The present experiment attempts to: (1) Test the generality of social attraction and the days effect by examining them with two different strains of rats and both sexes; (2) provide a new test of a possible fear-affiliation relationship by testing social attraction in two rat strains known to differ in fearfulness; and (3) see whether there is any sign of social discrimination or own-strain preference in rats by testing both same-strain and cross-strain pairings.

\section{METHOD \\ Design}

Sixteen same-sex pairs of rats were tested each day for 10 days in each of the three experimental conditions. Rat pairs consisted of either two albino rats, two hooded rats, or one albino and one hooded rat. Each rat was tested with the same partner throughout. Within each condition, half the pairs consisted of male rats and half of female rats. 